\title{
Solar Radiation assessed by CPTEC Model GL: A Comparison between Results with GOES and MSG over Northeastern Brazil
}

\author{
Juan Carlos Ceballos ${ }^{\mathrm{a}}$, Amanda Monteiro Galvão, \\ ${ }^{a}$ Center for Weather Forecast and Climate Studies, National Institute for Space Research (CPTEC/INPE), Brazil \\ ${ }^{\mathrm{b}}$ Universidade Salesiana (UNISAL), Lorena, Brazil
}

\begin{abstract}
Distribution of solar radiation over South America is daily assessed by the CPTEC's GL1.2 model using GOES satellite imagery (VIS channel). Meteosat Second Generation full-resolution imagery is also being ingested from 2007 on. VIS MSG images used for estimating solar radiation with essentially the same code GL show similar results over Northeastern Brazil (where lines-of-sight of both satellites have similar zenith angles, helping comparisons). This result encourages the integrated use of both satellites for monitoring of solar radiation over a large area including South America and Africa.
\end{abstract}

Keywords: solar radiation, GL model, GOES, MSG, South America

PACS: $n^{\circ} 92.60 \mathrm{vb}$

\section{INTRODUCTION}

Model GL version 1.2 runs operationally at CPTEC/INPE assessing daily solar radiation from GOES 10 VIS imagery. Besides basic hypotheses of the model about influence of atmospheric conditions on surface irradiance, the fundamental local variable is reflectance at satellite pixel (Ceballos et al. 2004; see also URL http://satelite.cptec.inpe.br - Radiação solar e atmosférica). Daily irradiation is obtained by time integration of local irradiance; therefore, a geostationary satellite is the best instrument for this task. Northeastern Brazil is equally observed by GOES 10 and MSG satellites, with similar (although opposite) viewing angles. This fact suggests that both satellites could assess solar radiation in this region with similar performance; on the other hand, they could be compared so that MSG estimates might be "validated" against GOES estimates. Last but not least, both estimates could be complementary in order to describe solar radiation over a large area extended from South America to Africa. This paper presents results of a comparison between those estimates.

\section{GL MODEL FOR GOES AND METEOSAT IMAGERY}

Structure of GL model is described in Ceballos et al. (2004) [see also URL http://satelite.cptec.inpe.br/radiacao/] and briefly illustrated in other paper in this issue [see ID paper 483]. Radiation flux is partitioned into VIS and IR interval; the first one is conservative, with a correction for $\mathrm{O}_{3}$ in the stratosphere; the second does not scatter radiation (clouds are opaque and absorb/reflect radiation only). $\mathrm{Cu}$ Cloud cover is assessed from VIS reflectance ( $\mathrm{R}>0.465$ defines total cover). Water vapor and carbon dioxide contents are only local physical parameters. In this context, considering that cloud reflectance dominates the signal observed in VIS channel and that cloud reflectance is nearly constant in VIS interval (King et al., 1992), it is evident that the same set of GL hypotheses could be applied to GOES (VIS) as well as to MSG SEVIRI ( $0.6 \mu \mathrm{m}$ channel) imagery. Eventually, the basic hypothesis of lambertian reflectance by earth-atmosphere system can be violated (Lubin et al. 1995) and differences be induced in GL results based on both satellites. For instance, Figure (1) shows the GOES 10 Imager VIS and MSG2 SEVIRI 0.6 $\mu \mathrm{m}$ images of Brazilian region at 1 August 20081500 UT. It is seen that they are essentially identical, except for a clear brightness difference due to sunglint position over Atlantic Ocean, North of Amazon mouth for GOES and North-East of Brazilian oriental coast for Meteosat. 

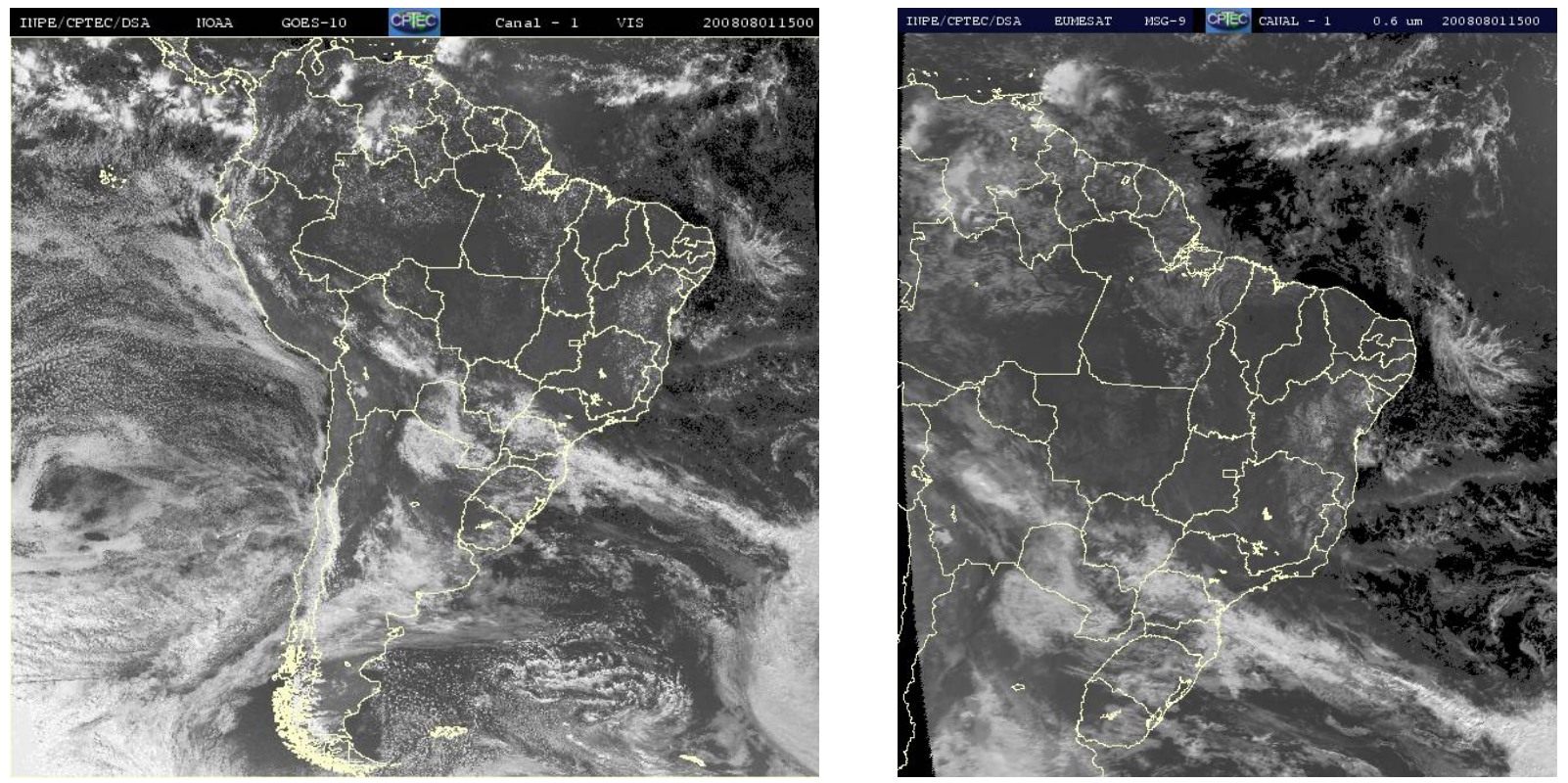

FIGURE 1. South American images in VIS spectrum: GOES Imager channel $1(0.55-0.75 \mu \mathrm{m})$ and MSG SEVIRI channel 2 (0.6 $\mu \mathrm{m})$. Both images are shown in rectangular coordinates (lon-lat), and correspond to 1 August 20081500 UT.

\section{RESULTS}

Model GL was applied to GOES and MSG imagery ingested CPTEC/INPE, choosing one image each half-anhour. Original satellite imagery was used (satellite-projection and a couple of files for co-location of pixels in a regular projection as in Figure 1), and the same set of set of physical hypotheses. The resulting files were samples for building daily cycles, or integrated to compare daily irradiation fields.

Figure 2 shows daily cycles of irradiance estimated in four sites with cloudy or rather clear situations. Red line corresponds to hourly mean irradiance provided by pyranomets of the Brazilian National Institute of Meteorology network. It is evident that both applications provide similar results, and that accuracy is substantially good. Site locations vary from eastern Brazilian coast (Recife, Ilheus) to inland station at Viçosa or a extreme-west located at Cuiabá. In some cases it is evident the difference induced by the presence of clouds and the different line-of-sight of each satellite. There is not an obvious rule to observe better estimate of any one of both satellites.

When considering integrated daily irradiance (Figure 3), it is seen that the difference of MSG related to GOES is substantially positive and lower than $+10-15 \mathrm{~W} \cdot \mathrm{m}^{-2}$ except for cloudy conditions, when difference is negative but lower than $35 \mathrm{~W} \cdot \mathrm{m}^{-2}$ (absolute value). The physical reasons for those behaviors are being analyzed. Anyway, the characteristic difference is lower than $4-6 \%$.

\section{CONCLUSIONS}

The quality of preliminary results suggests that GL irradiance fields obtained using GOES or MSG VIS imagery are substantially the same. Also, comparison with ground truth shows similar accuracy. Therefore, GOES as well as MSG could be used for obtaining similar results; and even integrated estimates from South America to Africa could be produced. Systematic analysis of results is being developed. 
modelo GL - Recife - PE 20070722

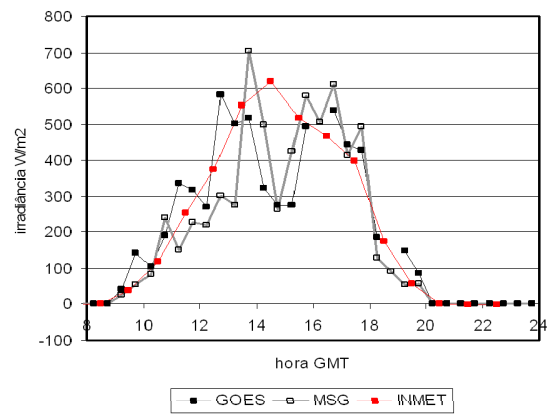

modelo GL - Cuiabá - MT - 20070722

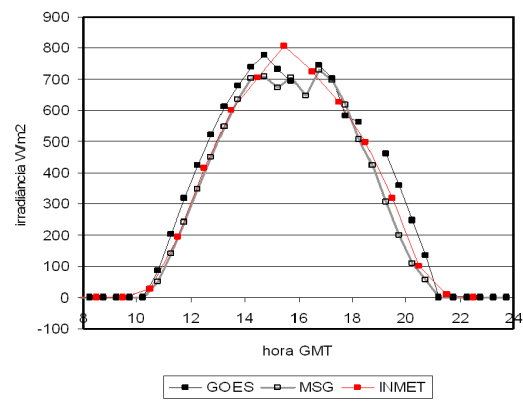

modelo GL - llhéus - BA - 20070722

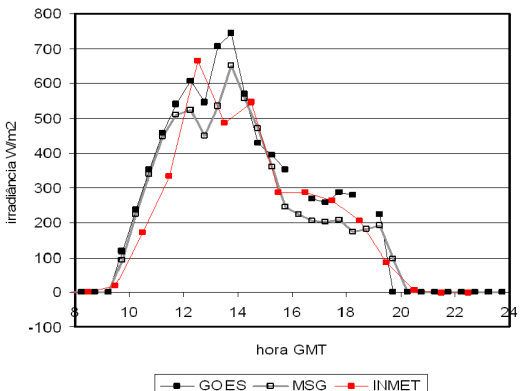

modelo GL - Viçosa - MG - 20070722

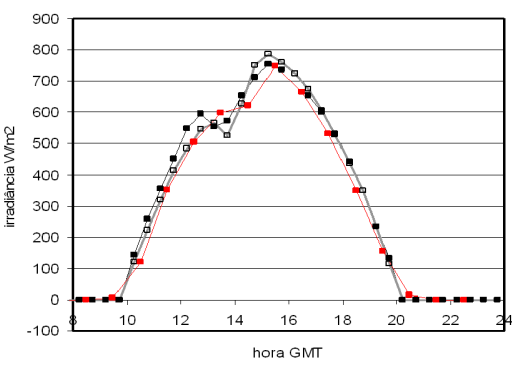

- GOES - - MSG - INMET

FIGURE 2. Diurnal cycle of solar irradiance obtained for sites in Brazil, using model GL applied to GOES 10 and MSG2 VIS imagery. Red line corresponds to mean hourly irradiance measured by pyranometer (Brazilian INMET network).

(a)

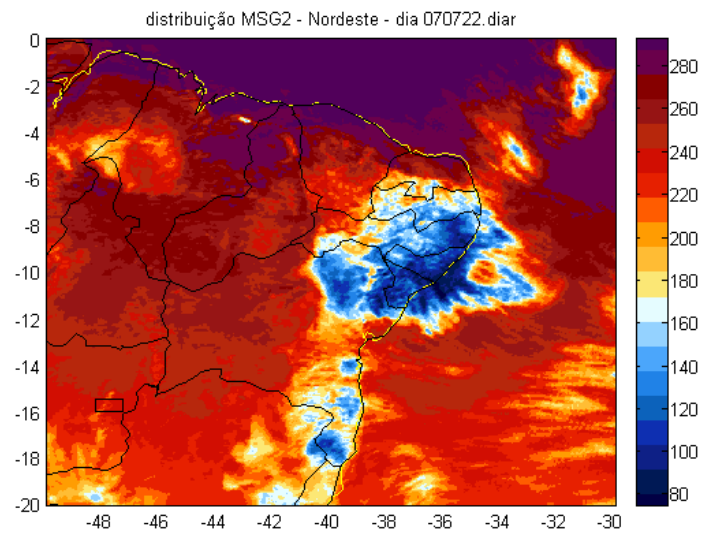

(b)

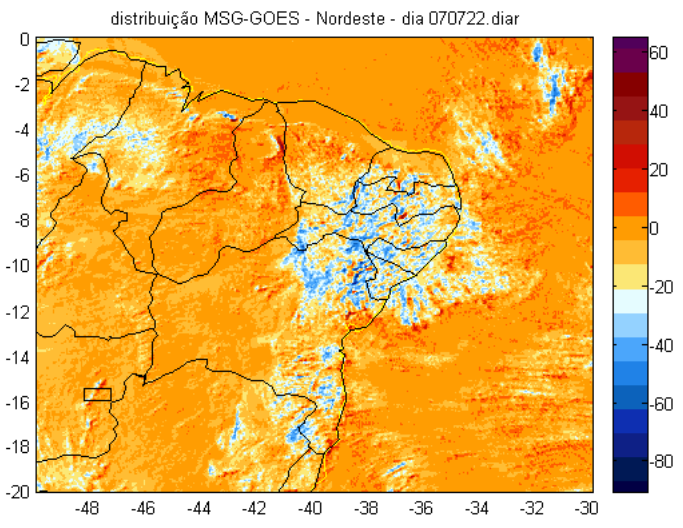

FIGURE 3. Solar radiation field (mean irradiance) over NorthEastern Brazil, 22 July 2007. (a) Meteosat estimate. (b) Difference of Meteosat estimate related to GOES-based results.

\section{ACKNOWLEDGMENTS}

The authors acknowledge Brazilian Research Council (CNPq) for recent support through research and scientific initiation fellowships. 


\section{REFERENCES}

1. J.C. Ceballos, M.J. Bottino, J.M. de Souza. A simplified physical model for assessing solar radiation over Brazil using GOES-E imagery. J. Geophys.. Research, v. 109, D02211, doi:10.1029/2003JD003531, 2004.

2. King, M. D., Y. J. Kaufman, W. P. Menzel and D. Tanr, 1992: Remote sensing of cloud, aerosol and water vapor properties from the Moderate Resolution Imaging Spectrometer (MODIS). IEEE Trans. Geosci. Remote Sens., 30, 227.

3. Lubin, D., and P. Weber (1995), The use of cloud reflectance functions with satellite data for surface radiation budget estimation, J. Appl. Meteorol., 34, 1333-1347. 